\title{
Chapter 3 \\ Country-Level Analysis: Power Sector, Energy Resources, and Policy Context
}

\section{Contents}

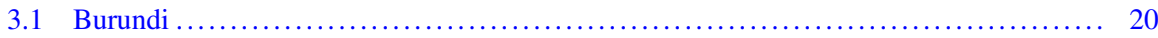

3.1.1 Electricity Access, Installed Capacity, and Non-renewable Reserves ........... 20

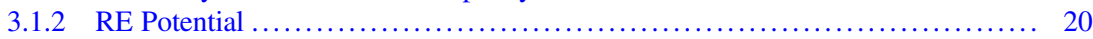

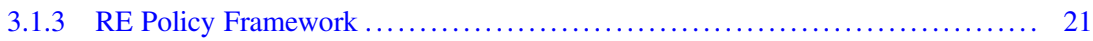

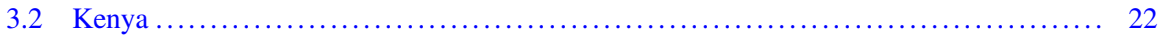

3.2.1 Electricity Access, Installed Capacity, and Non-renewable Reserves .......... 22

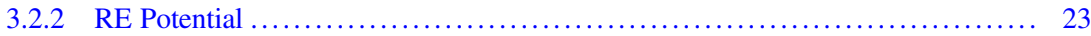

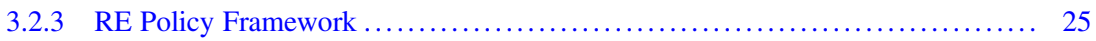

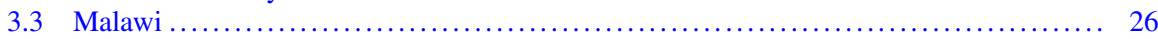

3.3.1 Electricity Access, Installed Capacity, and Non-renewable Reserves .......... 26

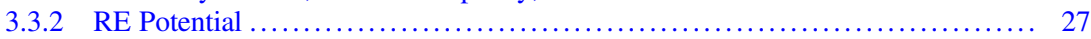

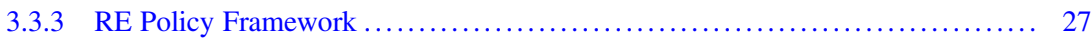

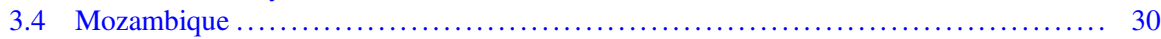

3.4.1 Electricity Access, Installed Capacity, and Non-renewable Reserves .......... 30

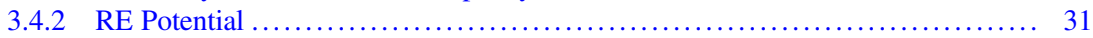

3.4.3 RE Policy Framework .......................................... 31

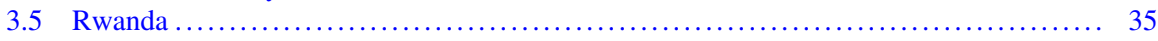

3.5.1 Electricity Access, Installed Capacity, and Non-renewable Reserves .......... 35

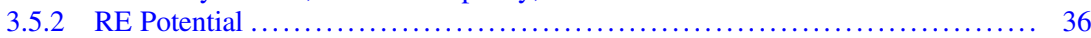

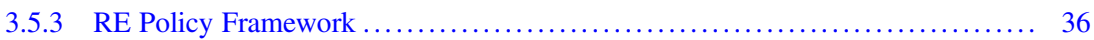

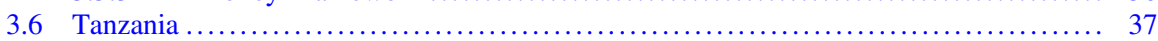

3.6.1 Electricity Access, Installed Capacity, and Non-renewable Reserves .......... 37

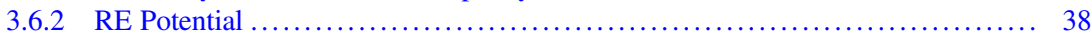

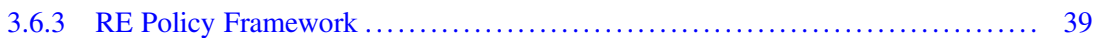

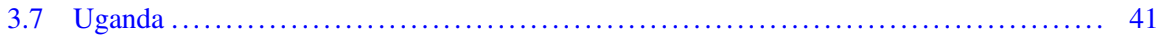

3.7.1 Electricity Access, Installed Capacity, and Non-renewable Reserves .......... 41

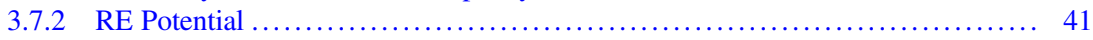

3.7.3 RE Policy Framework ......................................... 42

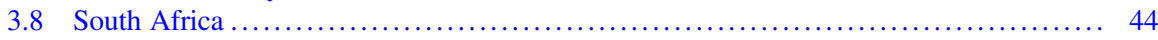

3.8.1 Electricity Access, Installed Capacity, and Non-renewable Reserves ............. 44

3.8.2 RE Potential .................................................. 45

3.8.3 RE Policy Framework .......................................... 46

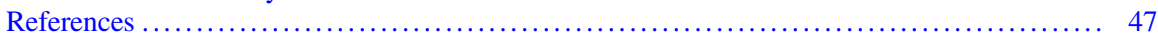

(C) The Author(s), under exclusive license to Springer Nature Switzerland AG 2019 


\subsection{Burundi}

\subsubsection{Electricity Access, Installed Capacity, and Non- renewable Reserves}

With an installed capacity of $41 \mathrm{MW}$ and a total generation of $300 \mathrm{GWh}$ in 2015 (United Nations 2015), Burundi is characterised by particularly low electricity access figures. Only $10 \%$ of the ten million inhabitants is served by electricity, with the rate reaching $35 \%$ in urban areas and dropping to $6 \%$ in rural areas (IEA 2017b). Households located in the capital Bujumbura account for the bulk of electricity consumption. Electricity represents however just $1.3 \%$ of the national energy consumption, and-as seen in Fig. 3.1-most of the generation capacity $(91 \%)$ comes from hydropower, with two small $(<50 \mathrm{MW})$ plants active in Lake Kivu, with the other main source of generation being represented by diesel plants (RISE 2017).

The national utility REGIDESO (Control and Regulation Agency for the Water and Electricity) benefits from a long-term legally established monopoly for electricity supply, transmission, and distribution. The distribution system is modest in bearing and extent, with $546 \mathrm{~km}$ of transmission grid and $337 \mathrm{~km}$ of distribution lines in place. This represents a further constraint to new capacity additions. Burundi has no fossil fuel endowments, and the country has been often struggling to import oil products to operate generators and plants.

\subsubsection{RE Potential}

Burundi has very large untapped potential for hydropower development (with a technical potential of $1700 \mathrm{MW}$, of which $300 \mathrm{MW}$ are seen as commercially viable) with four projects equating to $90 \mathrm{MW}$ currently being developed and four others being planned (Hydropower and Dams 2017). This potential could be highly beneficial to the filling of the growing supply gap in the Bujumbura capital area,

Fig. 3.1 Burundi's

electricity generation mix.

- Diesel Small Hydro

Source: Authors'

elaboration on US EIA

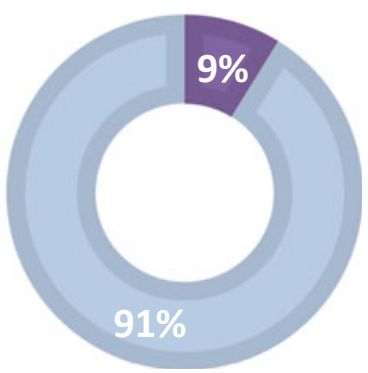




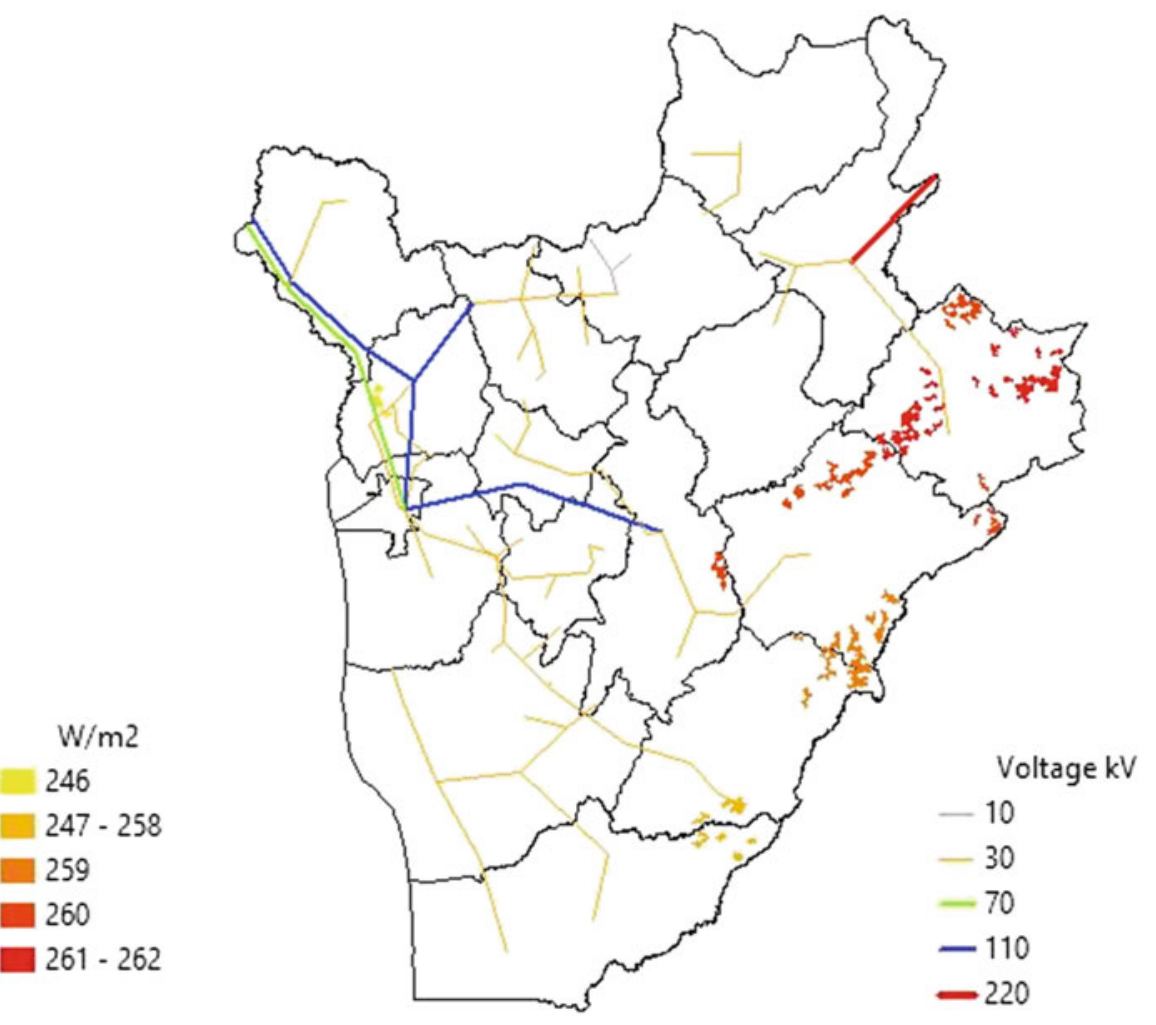

Fig. 3.2 Burundi electricity grid and most relevant locations in terms of solar potential. Source: Authors' elaboration on IRENA—REmap (2017)

where demand for electricity is soaring. Furthermore, $18 \mathrm{MW}$ of geothermal potential have been identified, and there are also areas with wind and solar potential suitable for exploitation (Fig. 3.2). Regarding the latter, as of January 2018 a 7.5 MW PV plant with a purchasing power agreement (PPA) already in place is under construction. Some use of PV for lightning and public buildings has also been reported.

\subsubsection{RE Policy Framework}

On the policy side, the Decentralized Rural Electrification Strategy (2015-2017) aims to maximize the social impact of decentralized RE to bring the benefits of modern energy technologies to rural children and families and promote transfer of skills and approaches to institutional, commercial, and community level structures. Furthermore, the medium-term Vision Burundi 2025, approved in 2011 by the 
UNDP and the Government of Burundi, aims to achieve an electrification rate of $25 \%$ by 2025 , reducing wood burning for heating and cooking in households while focusing on micro and mini renewable plants (including hydro). The country has indeed a fairly developed legal and policy framework for mini-grids (updated in 2015), including ownership and operation by private companies and the presence of duty exemptions for PV array and modules and for power generators. "Solar Electricity service with Mini Grids in Africa-Burundi" (SESMA-Burundi) as recently submitted a project aiming to bring online the first 7 mini grids of the country, currently at the feasibility study stage. To accomplish the electrification rate target set in Vision Burundi 2025, the Government has adopted a Decentralized Rural Electrification Strategy in 2015 and it plans to establish a National Agency for Renewable Energy and Energy Efficiency. The year 2011 saw the establishment of both the Burundian Agency for Rural Electrification (ABER) and of REGIDESO, which functions as the controller of water and electricity supply as well as of implementation, monitoring and application of tariffs. In compliance with law I/014 of year 2000, the public services of water and electricity provision are liberalized and regulated. That is, while the energy sector remains a public service under the responsibility of the state, its doors are as open to public as they are to private investors, selected through invitation to tender with specific criteria.

\subsection{Kenya}

\subsubsection{Electricity Access, Installed Capacity, and Non- renewable Reserves}

In Kenya around half of the installed capacity and of total generation stems from hydropower (Fig. 3.3).

Fig. 3.3 Kenya's electricity generation mix. Source: Authors' elaboration on US EIA

$\begin{array}{ll}\text { Biomass } & \text { Geothermal } \\ \text { Small hydro } & \text { Large hydro }\end{array}$

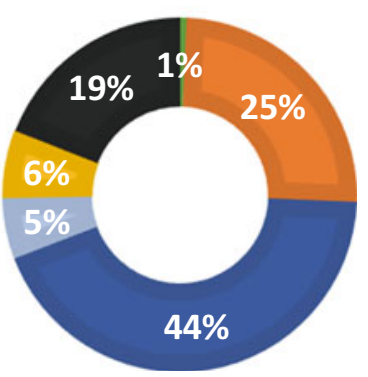


Total generation capacity sums to $2269 \mathrm{MW}$, which produced $9139 \mathrm{GWh}$ in 2015 (CIA 2017; Kenyan Energy Regulatory Commission). According to UNdata, hydropower is followed by thermal generation units (heavy fuel oil and diesel-fired) for installed capacity and electricity generated, while following ERC data this seems true only for installed capacity, given the higher reported relevance of electricity generated by geothermal units (which also account for around a fourth of total capacity in the country). There are also $25 \mathrm{MW}$ of wind and some biomass plants in place, although their contribution to electricity generation is still minimal. The industrial sector is currently the main consumer of electricity (around 57\%), followed by domestic customers $(26.3 \%)$ and by commercial and public services (refer to tables in the Appendix).

According to IEA (2017a), electricity access in Kenya stands at 65\% (78\% in urban areas and $60 \%$ in rural areas). Since 2012, when the electrification rate was around $20 \%$, the number of connected users has more than tripled as a result of government initiatives such as the Last Mile Connectivity Project, of private-public partnerships and international support and to the successful appearances of pay-asyou-go solar home system companies and innovative business models for mini-grid development. Thanks to this positive developments, Kenya is currently on track to reach universal electricity access by 2030 and it is identified as one of the virtuous examples in Sub-Saharan Africa in terms of electrification objectives (Gordon 2018). Still, more than half of the country's households are not yet connected to the national grid, and increasing efforts are required on the supply-side to satisfy a steeply increasing demand for power in cities.

Concerning fossil fuel endowments, in 2016 oil reserves amounting to 766 million barrels (and as much as 1.63 billion barrels of gross oil contingent resources) have been discovered in Lokichar, in the North of the country (Africa Oil Corp. 2016). The government plans to embark on large-scale oil production and build a pipeline to connect the fields with harbours on the East coast. The oil would predominantly be shipped to Asia. A heated debate is taking place on the set-up of the distribution mechanism of anticipated revenues.

\subsubsection{RE Potential}

Significant undeveloped hydropower resources exist, including 1449 MW of large hydro and $3000 \mathrm{MW}$ of small hydro, across 260 sites with good potential in areas with high population density and energy demand (Fig. 3.4). Feasibility studies for 12 sites with a combined capacity of $33 \mathrm{MW}$ were carried out in 2013, while other 14 are currently ongoing. Additionally, Kenya has around 20 feasible sites for the development of geothermal (which currently accounts for $27 \%$ of installed capacity), with a combined capacity between $5000 \mathrm{MW}$ and 10,000 MW (the governmentowned Geothermal Development Company is tasked with the integrated development of geothermal planning). The country also has a good potential for solar generation (see Fig. 3.5: Kenya receives solar irradiation of $4-6 \mathrm{kWh} / \mathrm{m}^{2} /$ day) and 
Potential (MW)

- $0.1-2.0$

- $2.0-4.0$

$4.0-6.0$

$6.0-8.0$

$8.0-9.8$

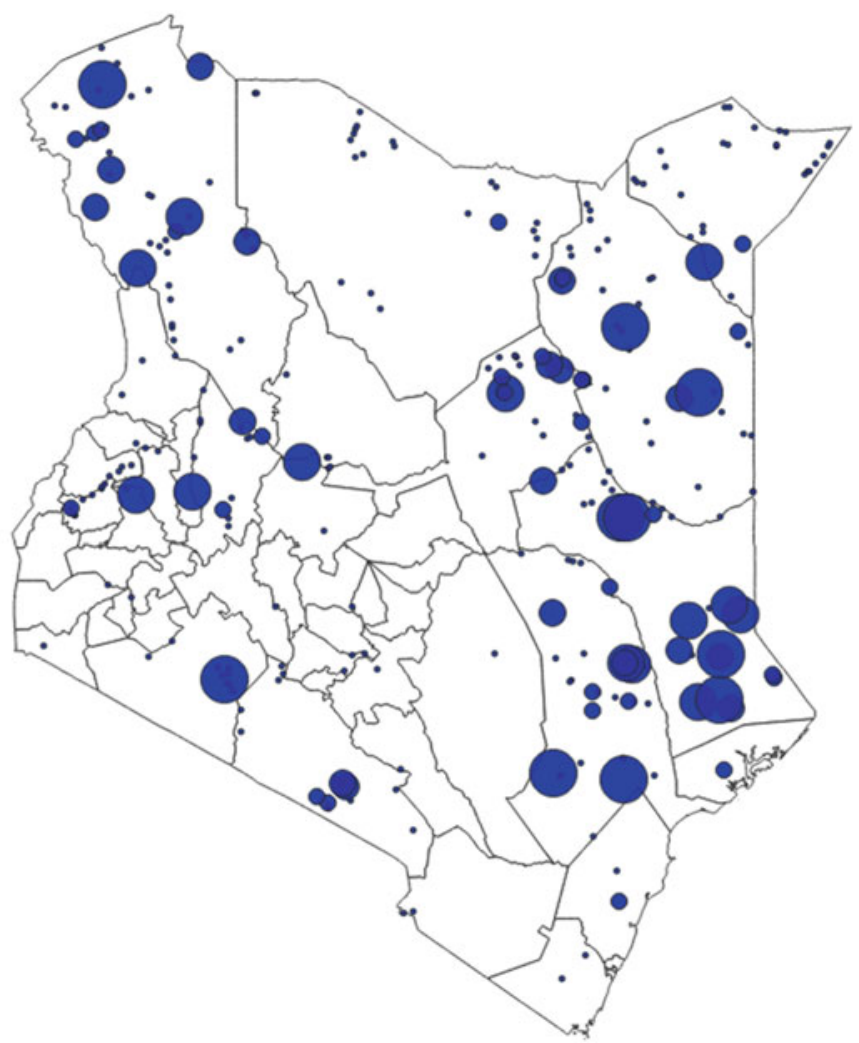

Fig. 3.4 Small hydropower potential in Kenya. Source: Authors' elaboration on Korkovelos et al. (2018)

a thriving market for small PV (12-50 Wp), with a governmental plan for providing electricity to educational, health, administrative and private sites far from the grid. 977 institutions have already been reached through such program, for an installed capacity of more than $1.5 \mathrm{MW}$ at peak time; in addition, isolated diesel stations are being transformed into diesel-solar hybrid with four other similar systems being currently deployed in rural areas. There are also a handful of large solar projects, each of around $40 \mathrm{MW}$, which received PPAs in late 2015. The country is also characterised by a high wind potential of up to $346 \mathrm{~W} / \mathrm{m}^{2}$ (with average wind speed exceeding $6 \mathrm{~m} / \mathrm{s}$ in many parts of the country), with one wind farm of $25.5 \mathrm{MW}$ being operated by KenGen and another one, Lake Turkana wind farm, whose $310 \mathrm{MW}$ operated by an independent power producer (IPP) should come on-line in late 2018 (Fig. 3.5) also figure as currently unexploited potential. The 19\% planned contribution of nuclear energy is also noticeable, with a first $1000 \mathrm{MW}$ plant expected to be operational by 2027 (currently in feasibility study phase). 


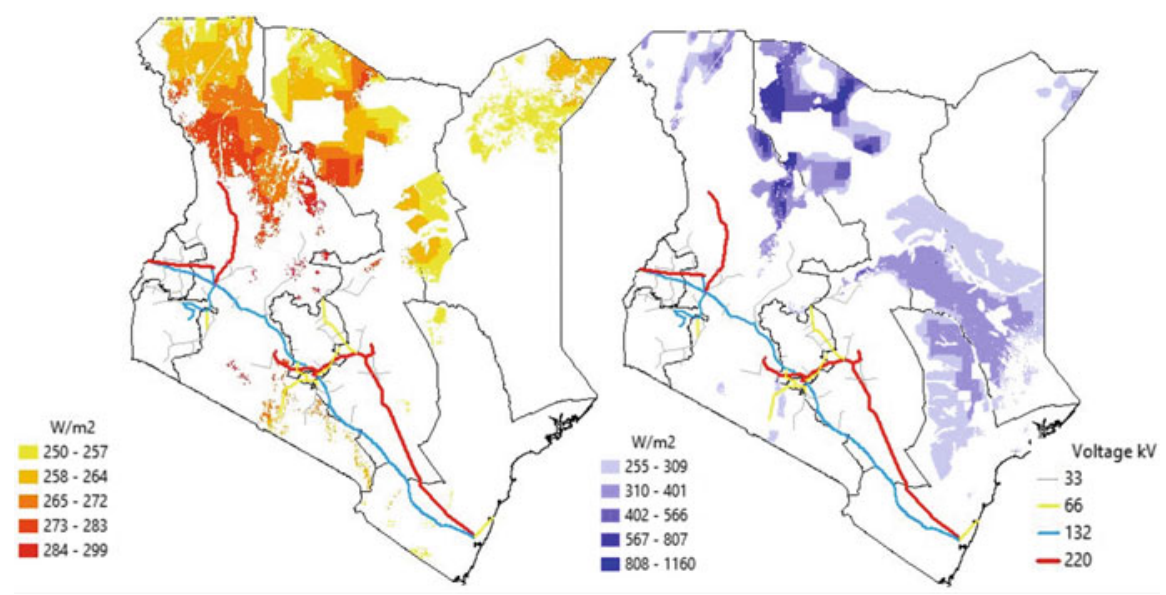

Fig. 3.5 Kenya electricity grid and most relevant solar and wind potential. Source: Authors' elaboration on IRENA—REmap (2017)

\subsubsection{RE Policy Framework}

The generation and transmission system of Kenya is based on a rolling 20-year least cost plan (Least Cost Power Development), which was updated in 2011 to reflect the Vision 2030 objectives. Such plan targets the contribution of geothermal energy to grow to $20 \%$ of installed capacity and the share of hydropower-currently the most relevant source of electricity in the country - to decrease to $5 \%$, while wind power should increase its share in the generation portfolio from less than 1-9\%.

The 2006 Energy Act set the objective of promoting the development of all RE sources, charging the Ministry of Energy with the creation of both an Energy Regulatory Commission - responsible of production, distribution, supply and use of RE-and of a national research agenda on RE. Since then, Kenya has also been one of the few EA-8 countries with tiered RE feed-in-tariffs (introduced in 2008, to be later revised in 2010 and 2012), i.e. differentiated by large-scale and small-scale projects (with $10 \mathrm{MW}$ as the threshold) and generation sources. The regulatory framework introduced tariffs at which IPPs are authorised to sell electricity at a fixed price for a fixed term of 20 years. Tariffs reflect the generation cost and they should not exceed the long-term marginal cost for on-grid systems.

Concerning recent energy policy initiatives, two key plans have been set forth: the Rural Electrification Master Plan and the Distribution Master Plan. The former sets the objective of achieving a $65 \%$ access to electricity by 2022 and full access by 2030. Clear steps and supporting instruments are defined. The Rural Electrification Authority is the main authority responsible for tracking progress of the plan. The latter, put forward in 2013, produced estimates of the long-term annual investment required in all distribution infrastructure, from $66 \mathrm{kV}$ to LV, up to 2030. To serve this purpose, the Kenya Energy Bill was passed in 2015 in order to establish a 
distribution licensee plan and to put into place the requisite electric supply lines necessary to enable any person in the licensee's supply area to receive electrical energy either directly from the licensee or from an accordingly authorised electricity retailer. Furthermore, in the coming years Kenya intends to also roll out an auctionbased development plan for wind and solar and to replace the ongoing feed-in tariff scheme, as well as introducing net metering for residential generation and to establish regulations for mini-grids (Climatescope 2017).

\subsection{Malawi}

\subsubsection{Electricity Access, Installed Capacity, and Non- renewable Reserves}

UNdata reports an installed capacity of 501 MW for the year 2014, while the publicly-owned electricity supply company of Malawi ESCOM (2017) and CIA (2017) refer to an installed capacity of $353 \mathrm{MW}$. The discrepancy between the figures likely stems from $210 \mathrm{MW}$ of self-producing diesel units not attached to the grid, and from rehabilitation work on certain power stations (e.g. undergoing dredging operation at the pond reservoir at Nkula Power Station). Note that the vast majority $(>95 \%)$ of grid-available capacity in Malawi comes from hydropower (Fig. 3.6), and due to rain-failure in 2015 and 2016 there has been a significant reduction in the hydro-based generation from ESCOM, which has effectively averaged around $200 \mathrm{MW}$. Further reduction in the available hydro capacity is expected due to continuously dropping water level in Lake Malawi as a result of both increased withdrawals and reduced runoff.

Overall, in 2015 electricity generation stood at $2120 \mathrm{GWh}$ (CIA 2017), with roughly $11 \%$ of the population being served by the grid. The proportion of urban residents with access to power is a magnitude larger than that of rural residents (49\% and 3\% respectively, IEA 2017a). Similar shares of electricity are being consumed

Fig. 3.6 Malawi's electricity generation mix. Large hydr Small hydro Diesel Source: Authors' elaboration on US EIA

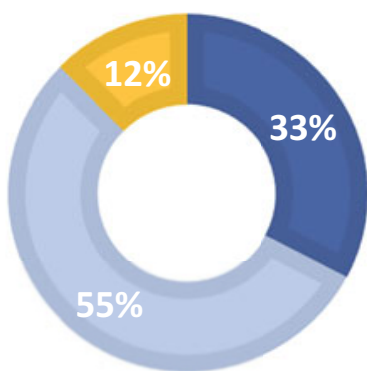


by the manufacturing and household services, which represent the bulk of total consumption.

With regards to fossil fuels, Malawi is endowed with 20 million tons of proven coal reserves (estimated resources are between 80 million and one billion tons), at four coal fields. Although up to now coal was mostly used for industrial heating, a $300 \mathrm{MW}$ coal plant to generate electricity is currently under development, with project planning at an advanced stage and commissioning expected by 2021. Coal would be imported from Mozambique by rail, given the plant's location close to the border between the two countries and the already existing nearby railway line. On the other hand, Malawi is not endowed with either oil or gas reserves, although it is locked in a border dispute with Tanzania over Lake Nyasa, which might contain both. No exploration will take place until the dispute is resolved.

\subsubsection{RE Potential}

Following Malawi Growth and Development Strategy III (2017-2020), environmental and social impact assessment studies for further hydropower projects (three stations of $350 \mathrm{MW}, 200 \mathrm{MW}$ and $120 \mathrm{MW}$ respectively) are currently under development. Malawi has also some solar (Fig. 3.7) and wind (Fig. 3.8) potential (which is currently undergoing a mapping project, refer to World Bank 2017), and although non-hydro renewables currently contribute very modestly to power generation, their share should increase in the near future with the development of 21 IPPs solar Schemes (3 of which already possess a PPA) that should increase the available grid capacity to $563 \mathrm{MW}$. However, as of today only two IPPs will have firm PPAs in place: HE Power for a $41 \mathrm{MW}$ hydro project, and IntraEnergy for a $120 \mathrm{MW}$ coal plant (Climatescope 2017). Malawi is not connected to power systems with neighbouring countries and therefore cannot benefit from its membership in international energy cooperation plans. A plan to link the national grid with Mozambique and Zambia for the purchase of at least $150 \mathrm{MW}$ of electricity is under development (Climatescope 2017).

\subsubsection{RE Policy Framework}

In Malawi, the Malawi Rural Electrification Program (MAREP) was last updated in 2017 and is currently undergoing its eight phase since its inception in 1980. It is supported by the Malawi Energy Regulatory Authority (MERA) and Rural Electrification Management Committee. Phase 8 foresees connecting to the grid 336 new trading centres by the end of 2018 , along with generation capacity additions. To attract foreign investment in the power sector, the country has also started an opening of the electricity market with a standardized PPA for IPPs to operate. In 2017, ESCOM also held its first RE tender, contracting $70 \mathrm{MW}$ of solar PV at four 


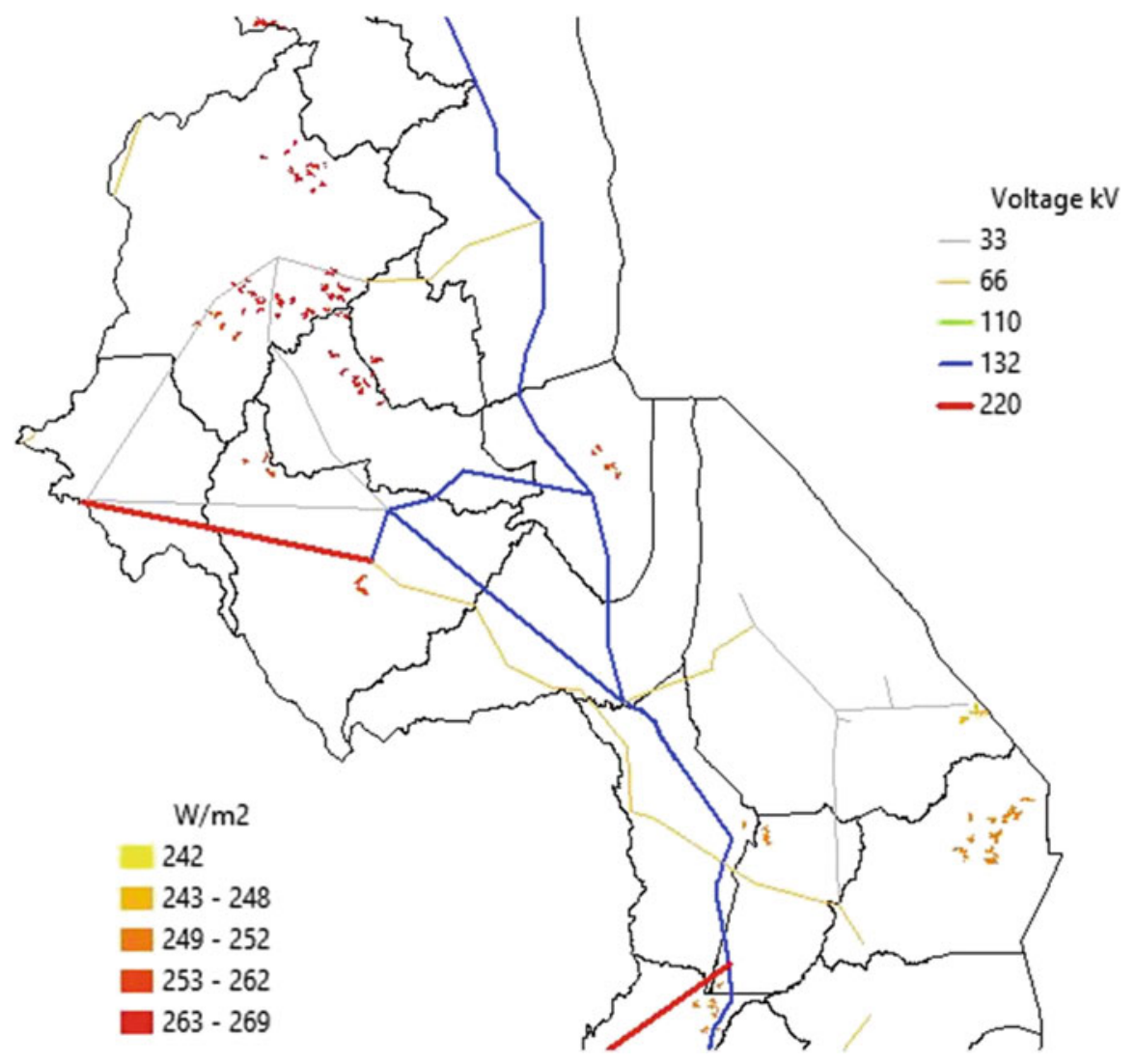

Fig. 3.7 Malawi electricity grid and most relevant locations in terms of solar potential, zoom. Source: Authors' elaboration on IRENA—REmap (2017)

sites. Furthermore, the existing Rural Electrification Programme uses revenue from a 3\% levy on electricity consumption and fuel import taxes to fund the extension of the national grid to business centres. The country aims to increase energy access to $30 \%$ by 2020 and $40 \%$ by 2050 . The National Energy Policy, still to be enforced, seeks to further diversify the energy mix with a major focus on renewable sources, such as solar and wind. The new energy policy is expected to raise the RE target to $22 \%$ by 2030 . Moreover, all the public institutions including hospitals and schools should gain access to electricity by 2035 through grid connection or mini-grid and off-grid projects (Climatescope 2017). Currently, those with access rely on isolated diesel generators. Furthermore, in 2012 the Malawi Energy Regulatory Authority (MERA) drafted a feed-in tariff plan including small scale hydro, PV, biomass, wind, and geothermal. For instance, for the case of hydro the tariffs apply for 20 years from the date of the first commissioning of the plant and they range between 0.08 and $0.14 \mathrm{USD} / \mathrm{kWh}$ depending on the project's scale and on the nature of the investor (firms or individuals), while for PV generation the feed-in-tariff (FiT) stands 

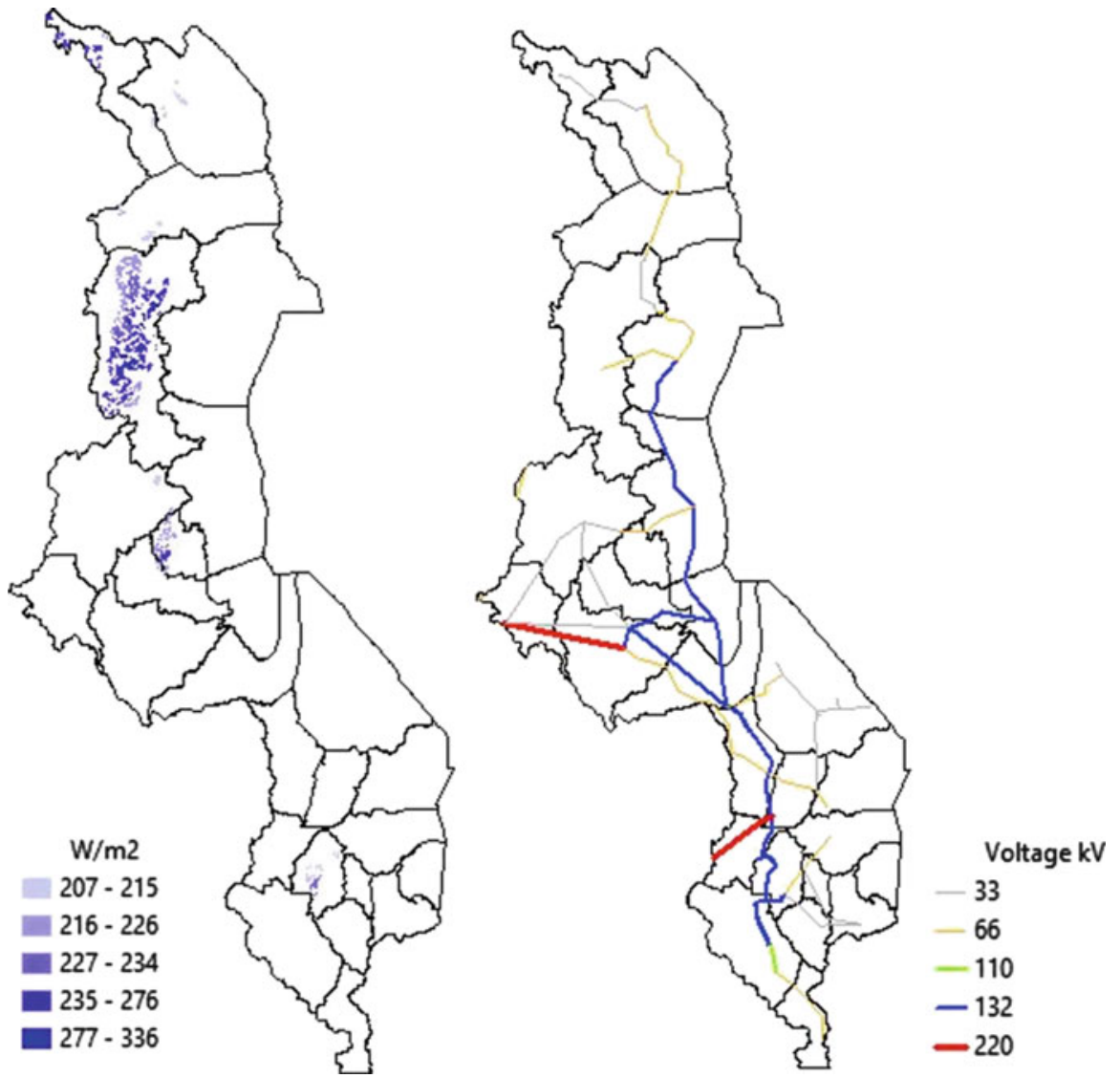

Fig. 3.8 Malawi electricity grid and most relevant locations in terms of wind potential. Source: Authors' elaboration on IRENA—REmap (2017)

at $0.20 \mathrm{USD} / \mathrm{kWh}$, for biomass and geothermal at $0.10 \mathrm{USD} / \mathrm{kWh}$, and for wind at $0.13 \mathrm{USD} / \mathrm{kWh}$. The policy also states that the FiTs policy shall be subject to review every 5 years from the date of publication. Any changes that may be made during such reviews shall only apply to RESE power plants that shall be developed after the revised guidelines are published. 
Fig. 3.9 Mozambique's electricity generation mix. Source: Authors' elaboration on US EIA
Large hydro $\square$ Natural gas

Small hydro

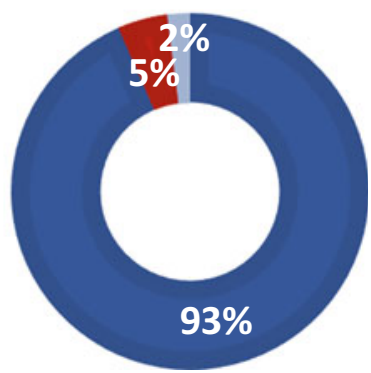

\subsection{Mozambique}

\subsubsection{Electricity Access, Installed Capacity, and Non- renewable Reserves}

The installed capacity in Mozambique is of 2687 MW (96\% is hydropower, as seen in Fig. 3.9), while generated electricity stands at 17,739 GWh (CIA 2017), the first among EA-7 countries.

However, the vast majority of the capacity is located at Cahora Bassa Dam (2075 MW), owned (92.5\%) by Electricidade do Moçambique (EdM) but serving predominantly South Africa (1575 MW) with two $533 \mathrm{kV}$ high voltage direct current lines connected to the plant. On the other hand, there is no interconnection between the plant and the southern part of Mozambique.

There is a discrepancy in thermal power generation data, standing at $359 \mathrm{MW}$ according to UNdata and only at $65 \mathrm{MW}$ for the World Bank. The difference might be partially due to a diverse way of considering the $175 \mathrm{MW}$ gas plant in course of development with SASOL. Differences are noted in the reported data about electricity consumption by sector. Overall, it seems that the share of electricity accruing to residential customers is just slightly smaller than that going to the different kind of industrial users.

Mozambique has significant fossil fuel endowments. Gas reserves are estimated at $2830 \mathrm{bcm}$ (ENI 2017a, b) and are pushing a strong development of the resource (prone to render Mozambique a regional leader), while coal reserves of good quality coking coal are estimated at 20 billion tons. The size and quality of reserves have led to the decision of developing a few coal-fired power stations: a $300 \mathrm{MW}$ plant in the north of the country (of property of a coal mine owner, currently finalising the financing phase), and two others-300 MW near Moatize and $150 \mathrm{MW}$ nearby Chirodzi-mostly to serve another coal mine, while excess electricity will be sold to the grid. However, the financing for the latter two plats is proving to be an issue. 


\subsubsection{RE Potential}

Mozambique has considerable unexploited electricity potential. The existing capacity of $2.1 \mathrm{GW}$ of hydropower is just over $10 \%$ of its potential $(19 \mathrm{GW})$, with a further $1 \mathrm{GW}$ of small hydro potential (Fig. 3.10). 351 hydro-projects for a total of $5.6 \mathrm{GW}$ are identified as high priority for development. Most of these projects (236) are below $5 \mathrm{MW}$. Although geothermal potential is still under investigation, at least $147 \mathrm{MW}$ of technically feasible capacity have been identified, of which 20 have been marked as a priority. Furthermore, of the $2.7 \mathrm{GW}$ of grid-connectable solar generation potential, only $599 \mathrm{MW}$ are currently considered for development due to the present limitations imposed by short circuit grids in place. Furthermore, solar PV also has a good potential for the off-grid electrification of rural areas (Fig. 3.11). So far it is estimated that 2.25 MW of PV have been installed in rural areas, while the market potential for off-grid pico-PV is estimated at $75 \mathrm{MW}$, with a further 4.6 MW of solar-diesel hybrid. Finally, the overall wind potential is estimated at $4.5 \mathrm{GW}$, with $1.1 \mathrm{GW}$ viable for connection, of which $230 \mathrm{MW}$ are considered a priority (Fig. 3.12). To exploit potential at a large-scale, Mozambique faces the great challenge of implementing improved electricity transmission and distribution systems.

\subsubsection{RE Policy Framework}

In 2009 the Policy on the Development of New and Renewable Energy explicitly promoted the use of RE resources for meeting the development needs of Mozambique, with a particular focus on increasing the access to modern energy in rural areas. The Policy outlined the framework of incentives for their development and suggested the creation of an investment priority plan. The Policy begun to be operationalised in 2011 through the Strategy for the New and Renewable Development 2011-2025, which divided actions between those directed to on- and off-grid development, with a focus on large scale PV programmes for lightning and water pumping and heating. It provided import tax exemption for RE equipment, VAT exemption for rural electrification and expansion projects, and corporate tax exemption for companies investing in either of the latter. Moreover, in 2011 the Public-Private Partnership law was also published, opening a space for IPPs, which however must sell electricity directly to EDM (the national electricity company) and negotiate prices on a contract-by-contract basis. As a result, in 2018 CRONIMET Mining Power Solutions and MOSTE have signed a MoU with FUNAE (the Rural Electrification Agency) to develop Mozambique's first privately developed and financed mini-grid (expected to generate up to $200 \mathrm{kWp}$ of solar power) on Chiloane Island, which will also be the largest pre-paid solar mini-grid in the country. Upon successful implementation of the Chiloane Island mini-grid, the consortium expects to develop a portfolio of 60 or more mini-grids across Mozambique. Further on the policy side, Decree 58/2014 


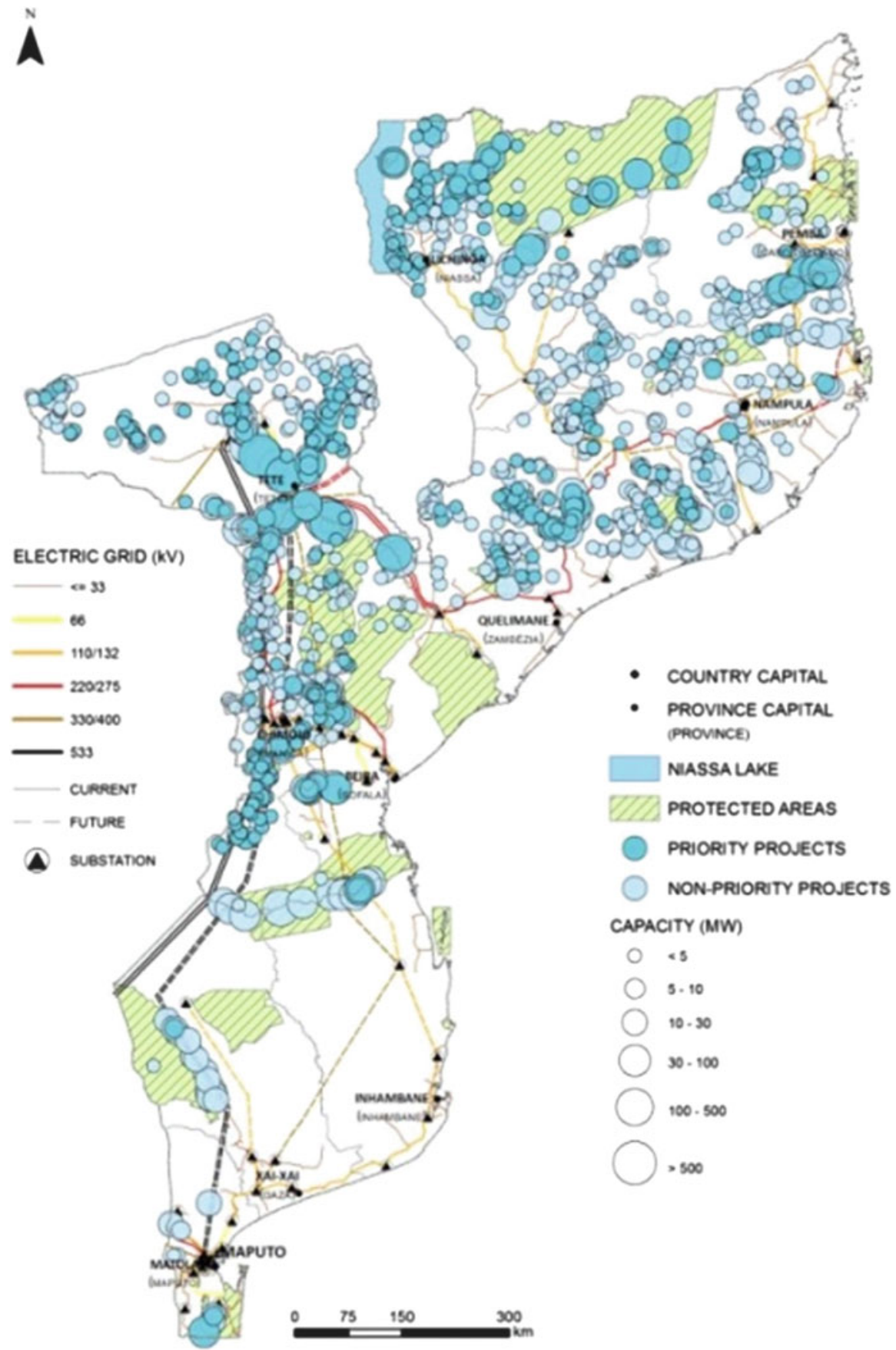

Fig. 3.10 Small hydropower sites examined by priority and potential, and the national electricity grid. Source: Renewable Energy Atlas Mozambique (2014) 


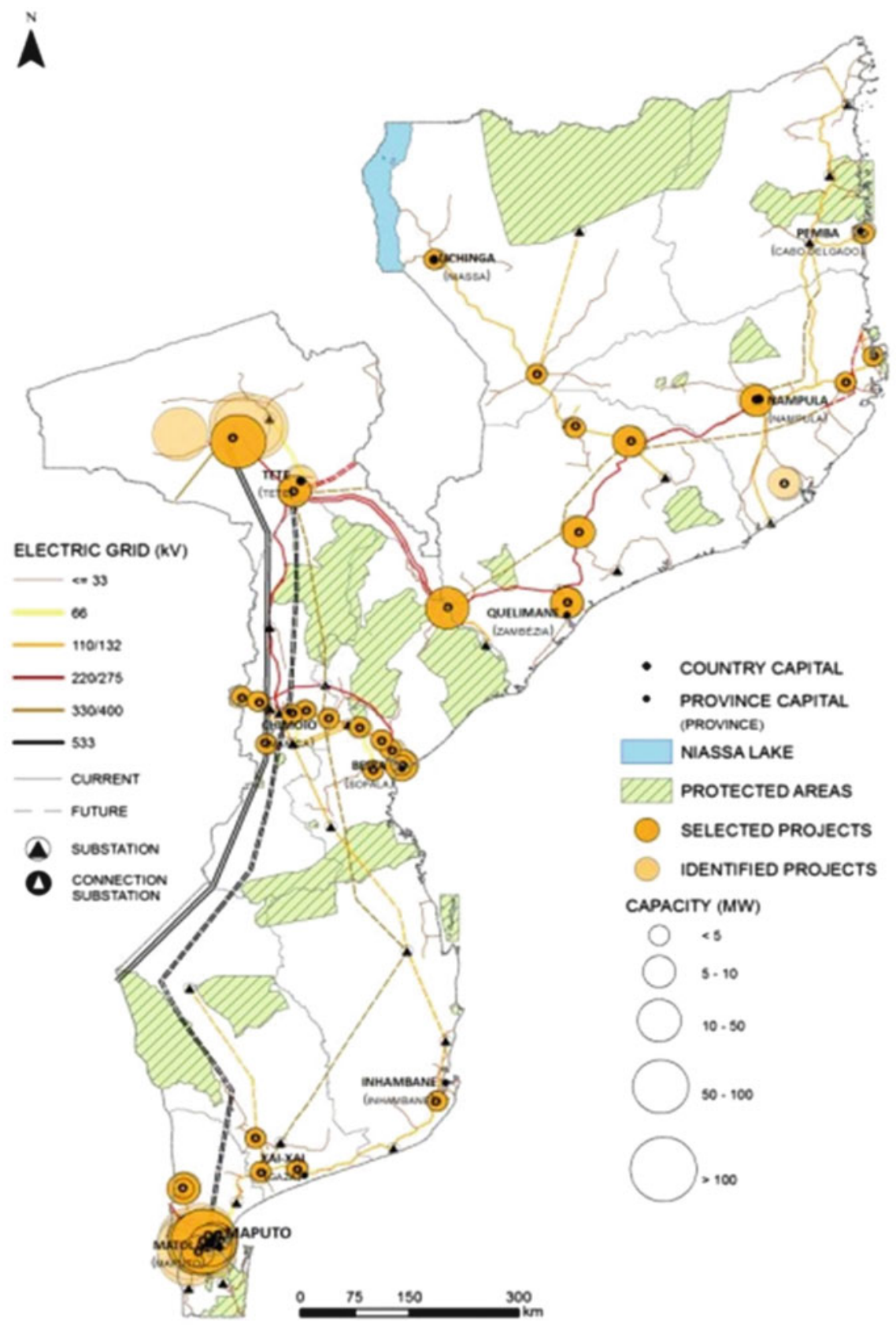

Fig. 3.11 Solar potential sites examined by status and potential, and the national electricity grid. Source: Renewable Energy Atlas Mozambique (2014) 

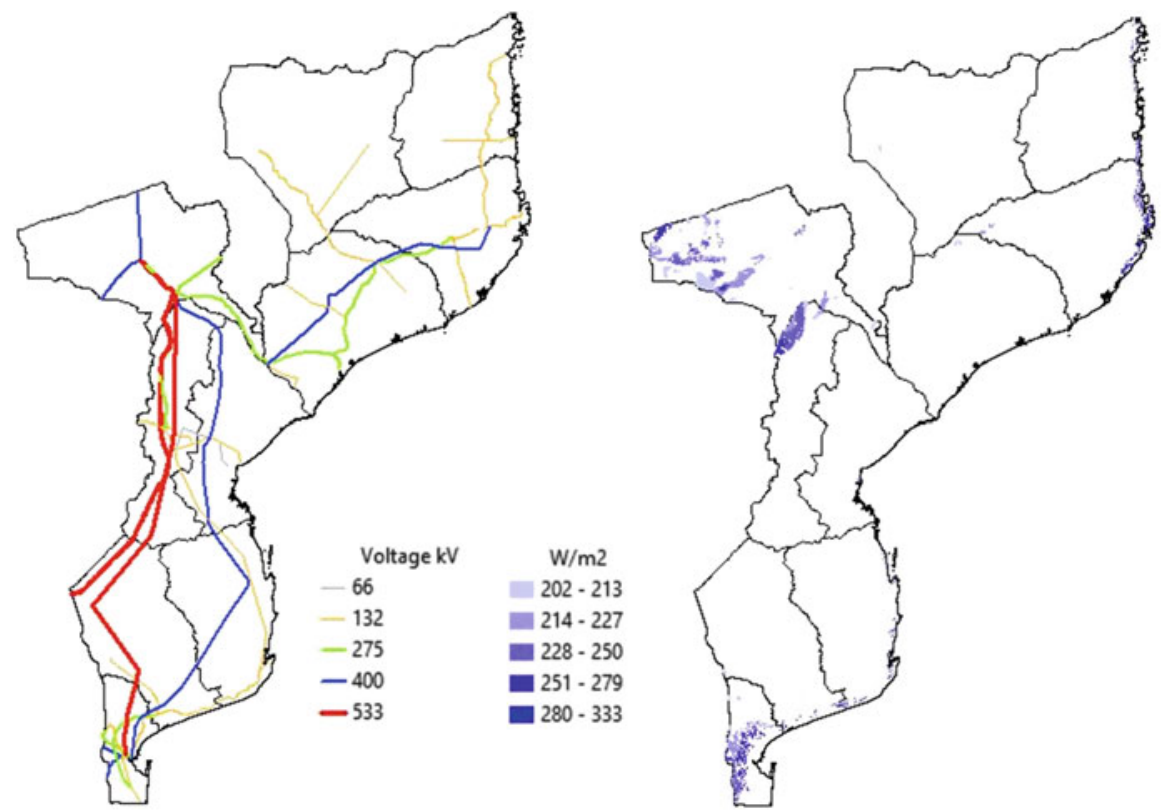

Fig. 3.12 Mozambique electricity grid and most relevant wind potential. Source: Authors' elaboration on IRENA-REmap (2017)

created Mozambique's feed-in tariff, which applies to biomass, wind, small hydro and solar projects from $10 \mathrm{~kW}$ to $10 \mathrm{MW}$. Prices vary according to technology and capacity (ranging between $0.07 \mathrm{USD} / \mathrm{kWh}$ for large biomass projects up to 0.22 $\mathrm{USD} / \mathrm{kWh}$ for solar PV up to $10 \mathrm{~kW}$ ). According to this Decree, all projects must sell electricity to the state-owned utility EDM. Although the decree is available, injection of power into the grid cannot happen yet as some regulation is still to be approved. Regardless, as of late 2017, the FiT mechanism was already undergoing revision. Mozambique is also reviewing the scope of the National Electricity Council (CNELEC), the power market regulator, in order to broad and strength its role. While this might help the FiT mechanism to gain more space in Mozambique power market, there is still a long road ahead before it becomes fully in force given that the stateowned utility EDM is sanctioned as off-taker of all power contracts while already being under considerable financial strain. 
Fig. 3.13 Rwanda's

electricity generation mix. Source: Authors' elaboration on US EIA
Small hydro Diesel $\mathbf{H F O}$ - Other

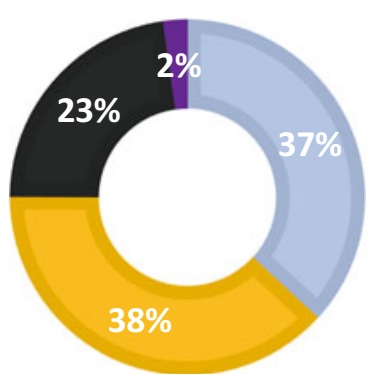

\subsection{Rwanda}

\subsubsection{Electricity Access, Installed Capacity, and Non- renewable Reserves}

In 2015 Rwanda generated most of its electricity (around 476 GWh, UNdata 2015) from hydropower (Fig. 3.13), which accounts for the bulk of installed capacity with an aggregate of $211 \mathrm{MW}$ according to Rwanda Energy Group 2017. The country also has $42 \mathrm{MW}$ of diesel and gas thermal plants and an $8 \mathrm{MW}$ PV plant in the Eastern Province, which represents $3 \%$ of the country's on-grid generation. The figures seem to suggest that a substantial growth in total capacity was witnessed in recent years thanks to the development of gas and solar generation, although some discrepancies between REG and UN data must be noted.

The government of Rwanda has been striving to increase electricity access, which, according to IEA (2017a), stands at 30\%, reaching $72 \%$ in urban areas while stopping at $12 \%$ in rural ones. According to the Rwanda Development Board (2017), residential access is at $40.5 \%$, of which $29.5 \%$ comes from grid and $11 \%$ from off-grid sources. This represents a very robust improvement from access rates of just $4 \%$ in 2008 and $12 \%$ in 2012.

On the consumption side, the bulk of the electricity produced in 2014 served households (for the year 2012 the figures available through the Ministry of Infrastructure report $51 \%$ of consumption from households, $42 \%$ from medium customers, $6 \%$ from public services and $1 \%$ of exports).

Rwanda has no oil reserves, but it is endowed with 55-60 bcm of NG located under Lake Kivu. These reserves have been earmarked towards NG fired generation, with an estimated potential of $350 \mathrm{MW}$ - the first $26 \mathrm{MW}$ of a $100 \mathrm{MW}$ project, called KivuWatt, started operating in May 2016. 


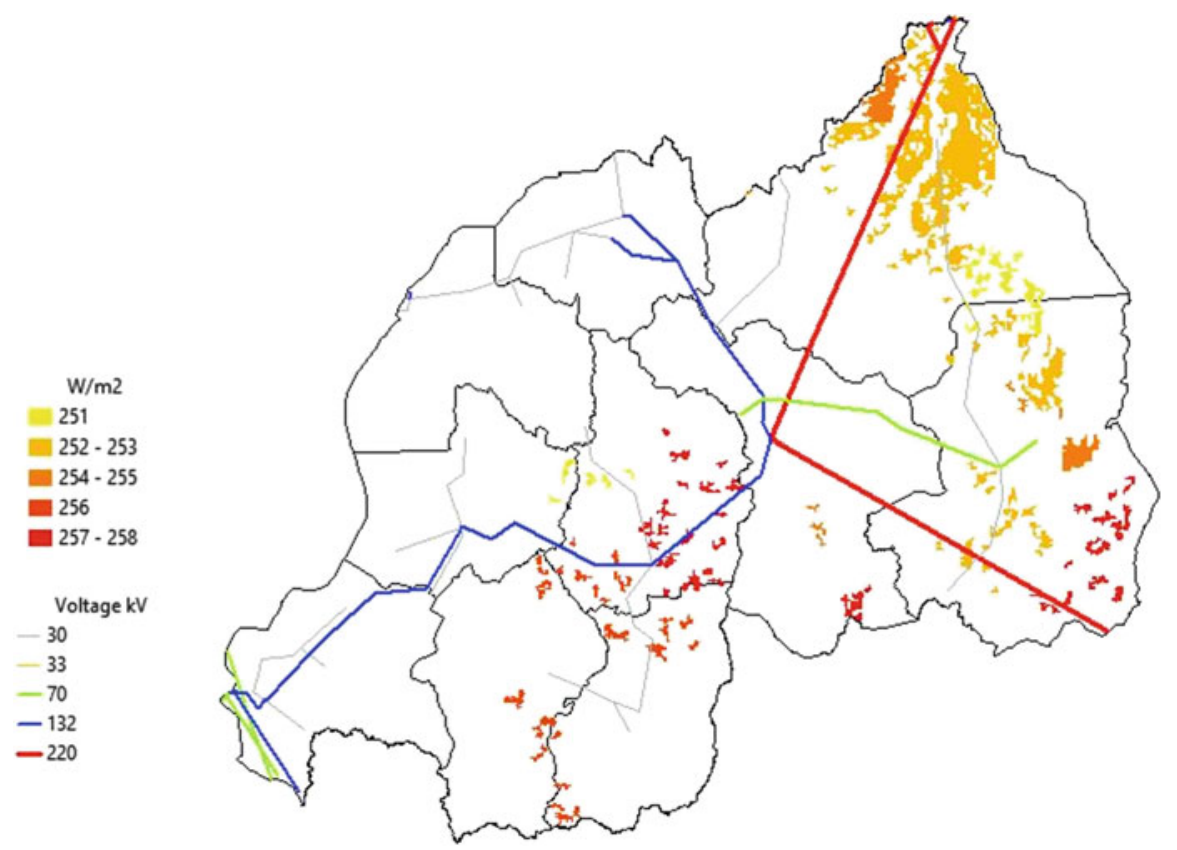

Fig. 3.14 Rwanda Electricity grid and most relevant locations in terms of solar potential. Source: Authors' elaboration on IRENA—REmap (2017)

\subsubsection{RE Potential}

The country has undeveloped potential in hydropower (300 MW), especially micro generation (but also inter-boundary projects with Burundi and DRC, $145 \mathrm{MW}$, at Ruzizi III, and with Burundi and Tanzania, $90 \mathrm{MW}$ at Rusumo Falls) as well as a geothermal (between 170 and $340 \mathrm{MW}$, a complete study of the reserves is yet to be undertaken), peat (up to $1200 \mathrm{MW}$ ) and solar potential (66.8 TWh, Fig. 3.14).

\subsubsection{RE Policy Framework}

The overarching aims of the government is to achieve $512 \mathrm{MW}$ of installed power generation capacity by $2023 / 24$ through increases in gas, solar, hydro, peat and interconnection capacity; to increase access to electricity to $100 \%$ of the population within the same time span, with off-grid electricity reaching $48 \%$ of the total; and to decrease the reliance on biomass from $86.3 \%$ of primary energy to $50 \%$ (by 2020). To achieve such objectives, different policy instruments have been adopted. In 2009, the Ministry of Infrastructure put forward its Electricity Access Roll Out Program, which is being implemented by the national Rwanda Energy Group. This has been 
supported by 377 million USD in its first stage, which successfully increased electricity connection by 250,000 units in just 4 years. The second phase is currently ongoing, and it is being backed up by 300 million USD necessary to achieve the $70 \%$ electrification rate objective. Moreover, the European Union and the World Bank signed a 200-million-euro financing agreement in 2016 to support off-grid electrification and a \$50 million agreement in 2017 to support Rwanda's Scaling Renewable Energy Program (SREP).

Over the past years, the government has also introduced an array of tools that have made on-grid development very attractive for the private sector. Since 2007, a combination of utility reforms, tenders, unsolicited proposals, a favourable tax regimes and donor support have all drawn the attention of private-sector players towards Rwanda, leading to 47 PPAs already signed to date. All IPPs must now participate in a competitive tender process, which is monitored by the Rwanda Utility Regulatory Authority (RURA). Rwanda's Renewable Energy feed-in tariff regulation was promulgated in February 2012. The Rwanda tariffs apply to small hydro from $50 \mathrm{~kW}$ to $10 \mathrm{MW}$. Contract terms are only 3 years, but the law specifies that the tariffs cannot be reduced. The tariffs will be reviewed in the second year of the program in order to be implemented in the third year. The Ministry of Infrastructure also subsidises $80 \%$ of new connections to the grid, providing potential customers with the ability to get a loan to cover their share of costs and to repay it to the electricity utility via a charge on electricity bills spread over 5 years. Additionally, Rwanda has signed a 30 MW PPA with Kenya, but the transmission infrastructure has not been built yet.

\subsection{Tanzania}

\subsubsection{Electricity Access, Installed Capacity, and Non- renewable Reserves}

Inconsistencies are found in the data on electric capacity in Tanzania. According to CIA (2017), in 2015 the installed capacity in Tanzania was 1583 MW, with slightly more than 50\% from hydropower (Fig. 3.15). A report from the Ministry of Energy and Minerals from 2014 (Electricity Supply Industry Reform Strategy and Roadmap 2014-2025) states the same installed capacity but attributes only $35 \%$ of it to hydropower. Finally, the December 2016 Power System Master Plan Update reports an installed capacity of $1390 \mathrm{MW}$, of which $43 \%$ comes from hydropower. In any case, electricity generation in 2015 was 6025 GWh (CIA 2017).

The electricity access rate reported in the IEA's WEO (2017b) is 33\%, with the usual discrepancy between urban $(65 \%)$ and rural $(17 \%)$ areas. Some differences between sources exists also with regards to the share of electricity consumed by different sectors. The Appendix reports both those for 2014 from UNdata and those for 2015 from the Power System Master Plan Update. 
Fig. 3.15 Tanzania's

electricity generation mix.

Source: Authors'

elaboration on US EIA
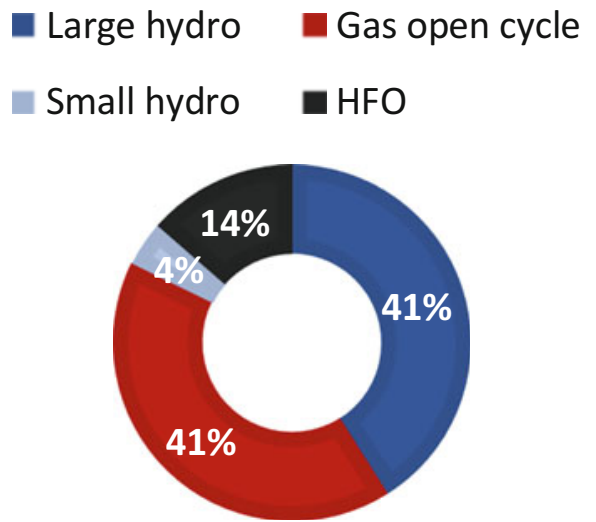

With regards to non-RE sources, Tanzania has $1600 \mathrm{bcm}$ of estimated NG reserves (ENI 2017a, b) and relevant coal resources (1.9 billion tons). The country has plans to develop four gas-fired power plants, amounting to $2733 \mathrm{MW}$ of capacity, and three coal-fired power plants, summing to $1400 \mathrm{MW}$.

\subsubsection{RE Potential}

Tanzania has significant potential for both large and small hydropower (480 MW for the latter), with SPPAs having been signed for 20.5 MW, and letter of intents for another 29.9 MW. However, similarly to neighbouring Malawi, the country has experienced extended periods of drought over the last few years, resulting in a complete switch-off of all hydropower plants in October 2015. Given that Tanzania also possess a geothermal potential of at least $650 \mathrm{MW}$, in 2013 the government created the Tanzania Geothermal Development Company in order to achieve the objectives of having $100 \mathrm{MW}$ of geothermal capacity in place by 2020 and $200 \mathrm{MW}$ by 2025. Tanzania would also gain from exploiting its solar energy potential, especially in its central region which receives 2800-3500 hours of sunshine per year with radiation of $4-7 \mathrm{kWh} / \mathrm{m}^{2}$ per day. The potential for grid-tied PV is 800 MW, which can cover $20 \%$ of day-time peak demand (Fig. 3.16) and, so far, one SPPA has been agreed upon for a $2 \mathrm{MWp}$ project in an isolated grid, for which a letter of intent signed, with several firms expressing interest in the development of 50-100 MWp solar parks. The government has removed VAT and import tax for most PV technology, reducing the end-user price, and different programs through the Rural Energy Agency are targeting rural areas through the promotion of PV adoption and the development of business models for solar companies. Furthermore, a $100 \mathrm{MW}$ wind project (Singida Wind Farm) is currently under development, with at least another grid-scale generation site having been individuated (Fig. 3.17). 


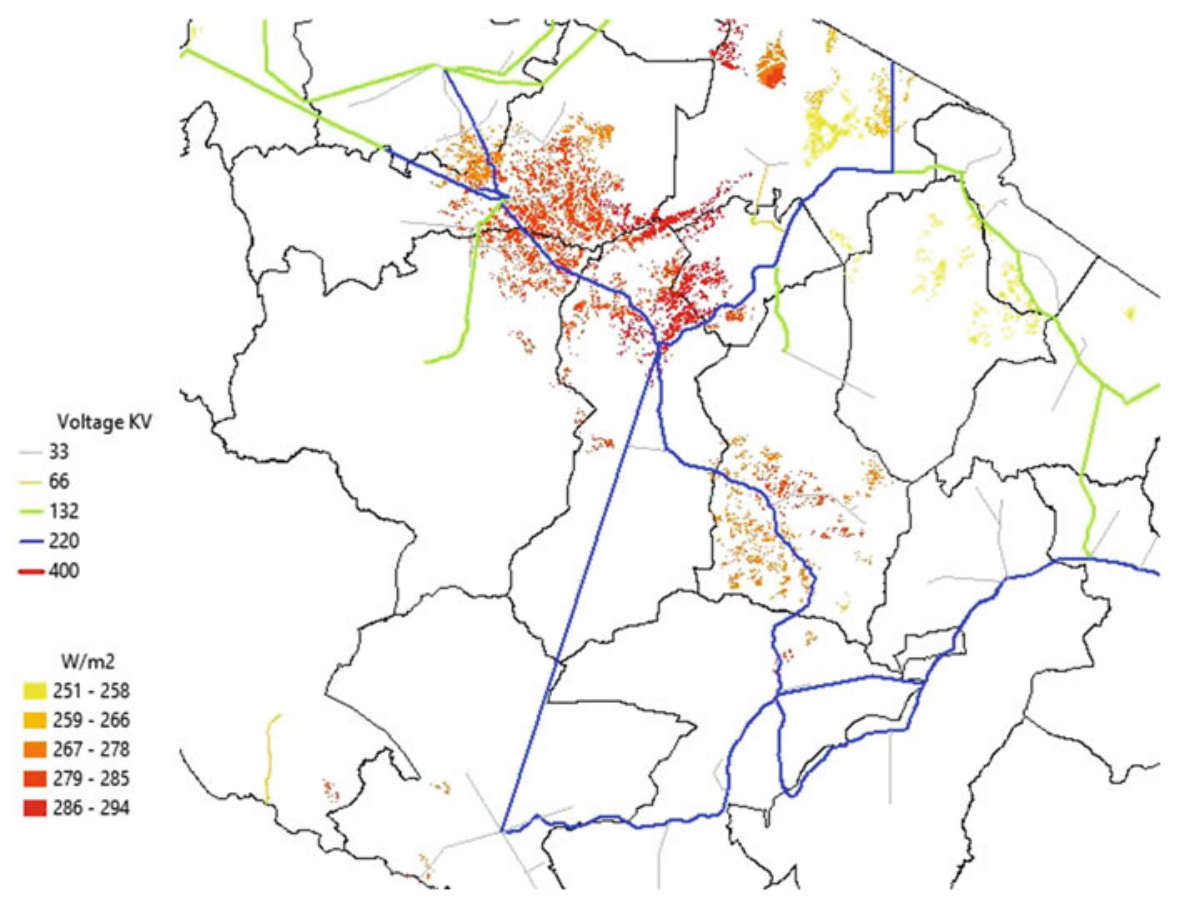

Fig. 3.16 Tanzania electricity grid and most relevant locations in terms of solar potential. Source: Authors' elaboration on IRENA—REmap (2017)

\subsubsection{RE Policy Framework}

On the policy side, the 2003 update to the 1992 National Energy Policy explicitly recognises the threat posed by climate change and calls for the promotion of the RE sector, which had so far received very little attention in the country, with capacity lacking through the whole value chain. The act mandates the establishment of an institutional and legal framework to address the technical, social and financial barriers for the diffusion of RE technologies. In 2008, feed-in tariffs were introduced to push such process but remained undifferentiated between different renewable technologies until their revision in 2015. After the revision, two different sets of prices are being applied to hydropower and biomass projects, while a bidding process is applied to solar and wind projects (although proposals developed before the revision are still subject to the old framework). Standardised PPAs are applied to all projects with capacity below $10 \mathrm{MW}$ while tariffs are negotiable for larger developments. Tariffs are cost-reflective and guaranteed for the duration of the PPA (up to 25 years) but are revised annually. Distinction is made between projects feeding the national grid and those serving mini-grids, with the tariffs also changing depending on the period of the year (wet or dry season). 


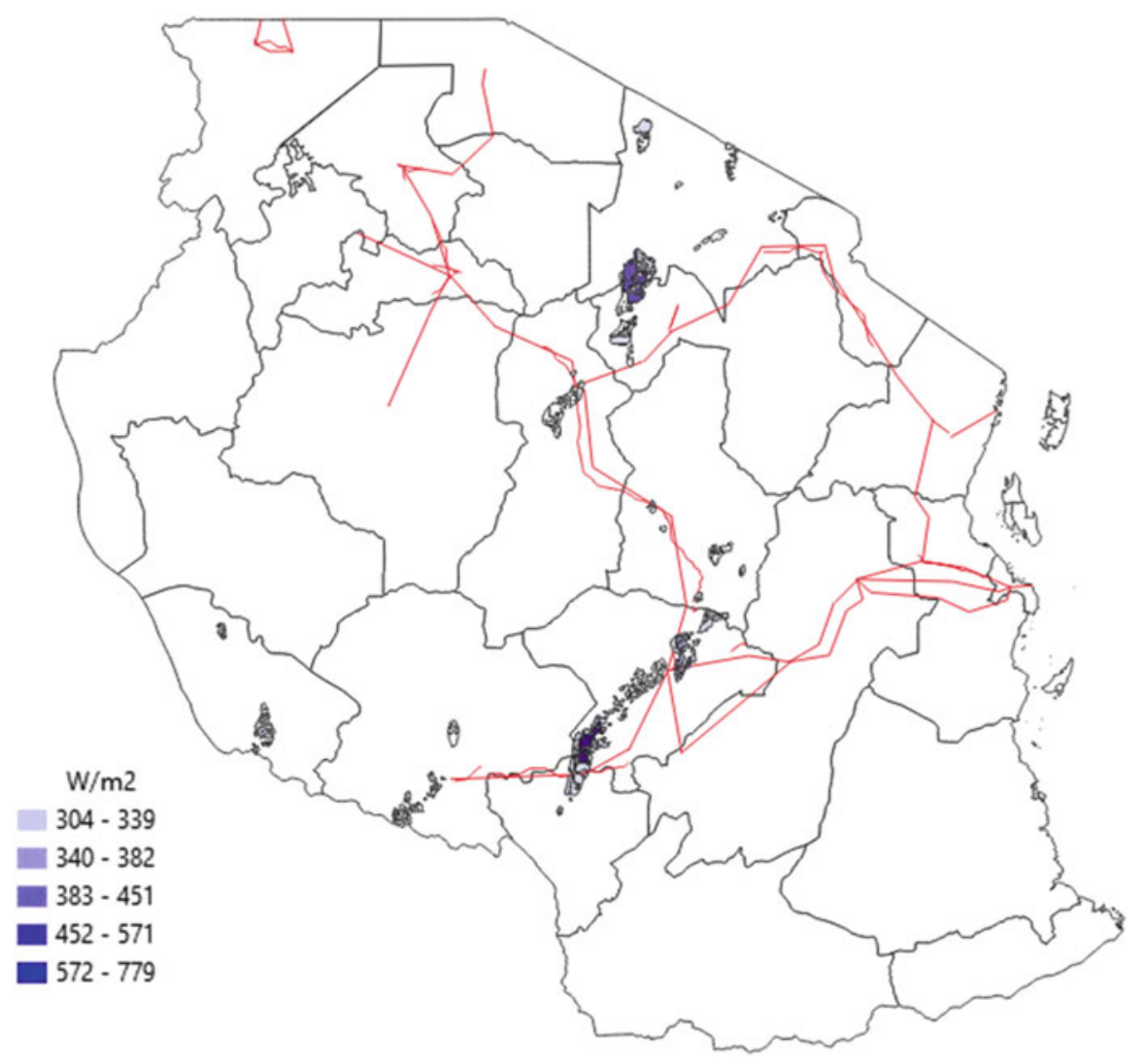

Fig. 3.17 Tanzania transmission grid and most relevant wind potential. Source: Authors' elaboration on IRENA—REmap (2017)

Moreover, Tanzania's second Five-Year Development Plan (FYDP II), presented in 2016, foresees a six-fold expansion of the power grid over the next decade. The plan sets a top-line installed base target of $10 \mathrm{GW}$ by $2025 / 26$, albeit the role of renewables has not been clearly defined. Currently, under the 'optimal expansion plan', the country would add ten times more fossil fuel (predominantly goal and NG) capacity than renewables by 2030. On the other hand, Tanzania was amongst the pilot countries for the World Bank's Scaling-up Renewable Energy Programme (SREP) and it prepared an investment plan for RE resources in 2012. Projects financed under the scheme target rural electrification through RE deployment and the creation of mini-grids. However, issues are holding back investment, including non-payment of fees by the utility to independent generators and retail electricity rates being set too low to unlock generation opportunities upstream. At the same time, a rich network of off-grid energy providers has emerged in rural Tanzania, where the distribution of pico-solar lighting products and the development of mobile-based, pay-as-you-go business models has thrived (Climatescope 2017). 
Fig. 3.18 Uganda's electricity generation mix. Source: Authors' elaboration on US EIA
Large hydro $=$ Small hydro $=\mathrm{HFO}=$ Biomass

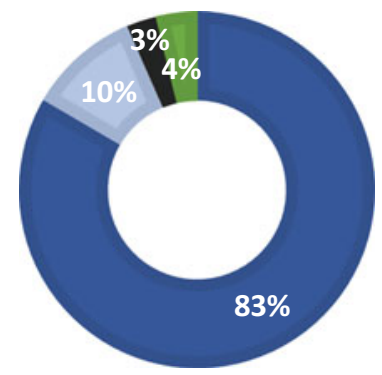

\subsection{Uganda}

\subsubsection{Electricity Access, Installed Capacity, and Non- renewable Reserves}

As of 2017, Uganda has a total installed capacity of 947 MW (Electricity Regulatory Authority), a relevant increase over the 2014 capacity of 883.3 MW (UNdata), with hydropower representing the main technology both for installed capacity (around $700 \mathrm{MW}$ ) and for electricity generated (around $90 \%$ of the total $3856 \mathrm{GWh}$ in 2017 , as shown by Fig. 3.18). A significant $18 \%$ of the total generation stems from small renewables, including small hydro, biomass co-generation (alone representing $4 \%$ of total capacity), and solar. Moreover, a recent grid capacity addition was achieved with a $10 \mathrm{MW}$ grid-connected solar plant, commissioned in December 2016.

The electricity access reported by IEA (2017a) is $19 \%$, with a connection rate of $23 \%$ in urban areas and of $19 \%$ in rural ones. The main consumer of electricity is the industrial sector (especially the iron \& steel industry) consuming twice as much electricity as the commercial and domestic sectors combined.

Concerning non-renewable resources, Uganda has 2590 million barrels of oil reserves, with production set to start in 2020, and $5 \mathrm{bcm}$ of gas reserves (ENI 2017a, b), most of which is associated gas.

\subsubsection{RE Potential}

In addition to its installed capacity, Uganda has an untapped hydropower potential of around $2000 \mathrm{MW}$ (Fig. 3.19), both in large and in small hydro. With regards to the former, 2 new plants with a combined capacity of $780 \mathrm{MW}$ should be online by the end of 2018 and a further 3 with a combined capacity of $1630 \mathrm{MW}$ are planned by 2026. Regarding the latter, in 2015 alone 13 small hydro projects (72.6 MW) underwent feasibility studies, 6 of which (36.4 MW) were in the process of licensing 


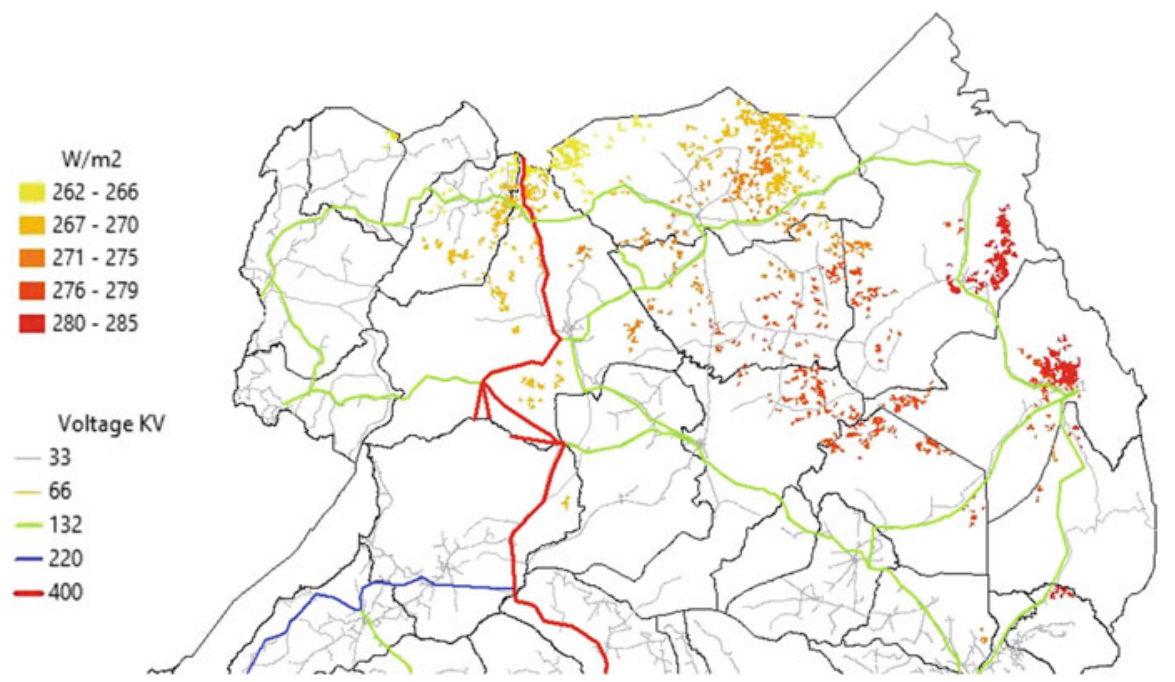

Fig. 3.19 Uganda Electricity grid and most relevant locations in terms of solar potential. Source: Authors' elaboration on IRENA—REmap (2017)

and discussion towards striking PPAs, while 11 other projects (53.8 MW) were in the pre-feasibility study stage.

Given that Uganda borders the western part of the East African Rift Valley, there is at least some geothermal potential, currently estimated at $450 \mathrm{MW}$. A prefeasibility study was undertaken for a $150 \mathrm{MW}$ geothermal plant (KATWE project in Kasese), which resulted in a non-financial PPA signed by the government, a consortium of local IPPs and an American company. Geothermal exploration is addressed using the mining act, which grants a 3-year exploration licence to investors. However, the absence of a dedicated policy framework is seen as one of the main obstacles for the development of the sector.

Uganda also has a developed market for residential PV systems (6000 households and 2000 institutions have installed panels for a combined capacity of $1.1 \mathrm{MW}$ as of 2014) and its first grid-level solar plant (10 MW) has been connected to the grid in December 2016 and should be serving electricity to 40,000 households located in nearby provinces. A second $10 \mathrm{MW}$ plant came online in 2017 (Fig. 3.20 for solar potential). Wind power potential is only moderate within the country and is most suitable for wind mills of $2.5-10 \mathrm{kV}$ capacity, which would be appropriate for small scale electricity generation or water pumping.

\subsubsection{RE Policy Framework}

Uganda is one of the few EA-8 countries to have liberalized its energy market: generation, transmission and supply were rendered competitive in 2001. Overall, 


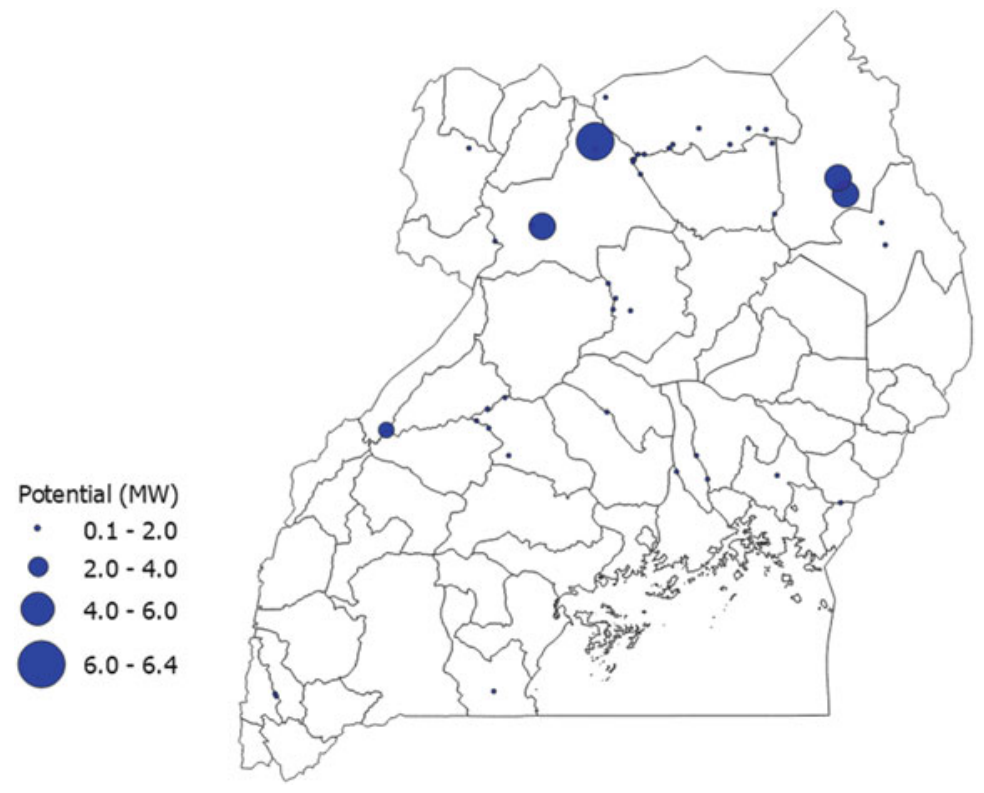

Fig. 3.20 Small hydropower potential in Uganda. Source: Authors' elaboration on Korkovelos et al. (2018)

under the 2013-22 Strategy and Plan, the Rural Electrification Agency aims to connect over 1.4 million customers to the main grid. The Agency plans to increase today's $19 \%$ rural electrification rate to $26 \%$ by 2022 , with the ultimate goal of universal access by 2035. In this direction, the 2007 Renewable Energy Policy was approved with the overall goal of increasing the share of RE (including hydro) in Uganda's energy consumption from $4 \%$ to $61 \%$ of the total by 2017 , with a series specific capacity targets for different sources. The policy aims at increasing access to modern, affordable and reliable energy to eradicate poverty in the country. This is to be achieved through the public and private development of the large hydropower potential in the country and through the promotion of various technologies (such as mini-hydro, PV and solar water heaters) in rural and urban poor areas. Significant progress has hitherto been achieved, with more than $400 \mathrm{MW}$ of large and mini hydropower capacity additions (and additional $900 \mathrm{MW}$ expected to be completed by 2020), and $20 \mathrm{MW}$ of solar completed between 2016-2017 and additional hundred-MW projects under development.

The Uganda Energy Capitalisation Trust was also created as a credit support facility to help realise the objectives of the policy, which are however currently still out of reach. The Renewable Energy Act also introduced feed-in tariffs for plants with a capacity below $20 \mathrm{MW}$ and PPAs for RE (which were later standardised in 2014), while also setting preferential tax treatment and accelerated depreciation. The scheme was revamped in 2013 ("Get FiT" program) and now provides a top-up payment on the feed-in tariffs for the first 5 years of operation, an insurance against 
Fig. 3.21 South Africa's electricity generation mix. Source: Authors' elaboration on US EIA
Coal $\square$ Nuclear $\square$ Large hydro $\square$ Gas open cycle

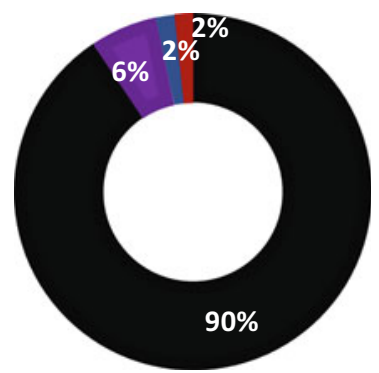

off-taker risk and simplified access to private finance. Tariffs differ by technology and the cumulative capacity limits for the tariff payment are set to increase over time. A $45 \%$ subsidy on all solar power equipment has also been in place since September 2007. Furthermore, credit-enhancement and support instruments (including technical assistance for early stage grid-scale project development and working capital for pay-as-you-go off-grid solar providers) are available to the private sector for both on- and off-grid projects (Climatescope 2017).

\subsection{South Africa}

\subsubsection{Electricity Access, Installed Capacity, and Non- renewable Reserves}

The installed capacity of South Africa is greater than that of all other Sub-Saharan African countries combined. According to ESKOM, the national utility responsible for $96 \%$ of electricity generation, in 2016 the capacity stood at 46,963 MW. Thermal generation (in particular from coal) represents the bulk of the capacity of the country (Fig. 3.21). In addition, South Africa is the only country in EA-8 which currently exploits nuclear energy (i.e. two nuclear reactors generate $5 \%$ of the country's electricity).

Generated electricity was estimated at 252,578 GWh in 2014 (UNdata), with an overall electricity access rate of roughly $86 \%$ with only minor differences between rural and urban connection rates. (IEA 2017a). The main electricity consuming sector in the country is the industrial sector, which accounts for $60 \%$ of demand-including mining and quarrying, non-ferrous metal, and chemical and petrochemical production. The household sector is responsible for the consumption of $19 \%$ of the electricity generated and commercial and public services for $14 \%$.

Concerning fossil fuels, South Africa is one of the top-10 producers of coal worldwide and sixth for coal export, with estimated reserves of hard coal equal to 66.7 billion tons. Coal exports are anticipated to increase by $28 \%$ by 2025 due to 


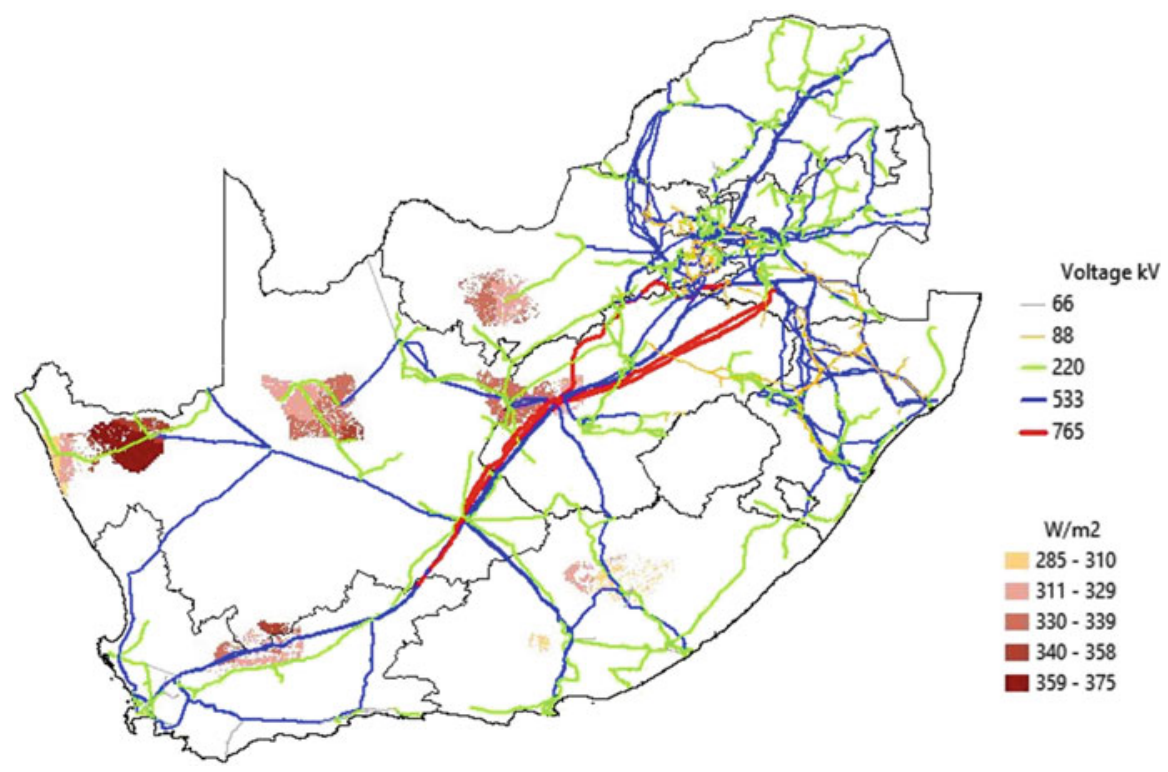

Fig. 3.22 South Africa electricity grid and most relevant CSP potential. Source: Authors' elaboration on IRENA-REmap (2017)

new coal plants becoming active. On the other hand, despite extensive exploration of coastal waters, only marginal gas discoveries have been made, so that gas infrastructure in the country is limited, although shale gas and coal bed methane might be present in the South Karoo Basin.

\subsubsection{RE Potential}

South Africa has also great unexploited endowments of RE, and the aim of the government is to achieve $9 \%$ of total electricity generation and $26 \%$ of installed capacity from renewables by 2030. Since the launch of the Renewable Energy Independent Power Producer Programme (REIPPP) in 2011-a competitivebidding program backed up by an independent authority ad-hoc established with the aim of delivering sustainable power to the grid and creating jobs and fostering local development-more than $5 \mathrm{GW}$ of renewables have been procured through four successive rounds. High potential exists for both solar and wind (Figs. 3.22 and 3.23). South Africa has one of the highest levels of solar radiation in the world, with an area of high radiation equal to $194,000 \mathrm{~km}^{2}$. If only $1 \%$ of this area were to be developed as CSP, the generation potential would be of $64 \mathrm{GW}$. As of 2013, the target for PV and CSP for 2030 are of $9.77 \mathrm{GW}$ ( $2 \mathrm{GW}$ already procured) and of 3.3 GW (400 MW already procured) respectively. The Integrated Energy Plan of 2016 calls for incentives to large scale CSP with industrial steam application in the short/ 


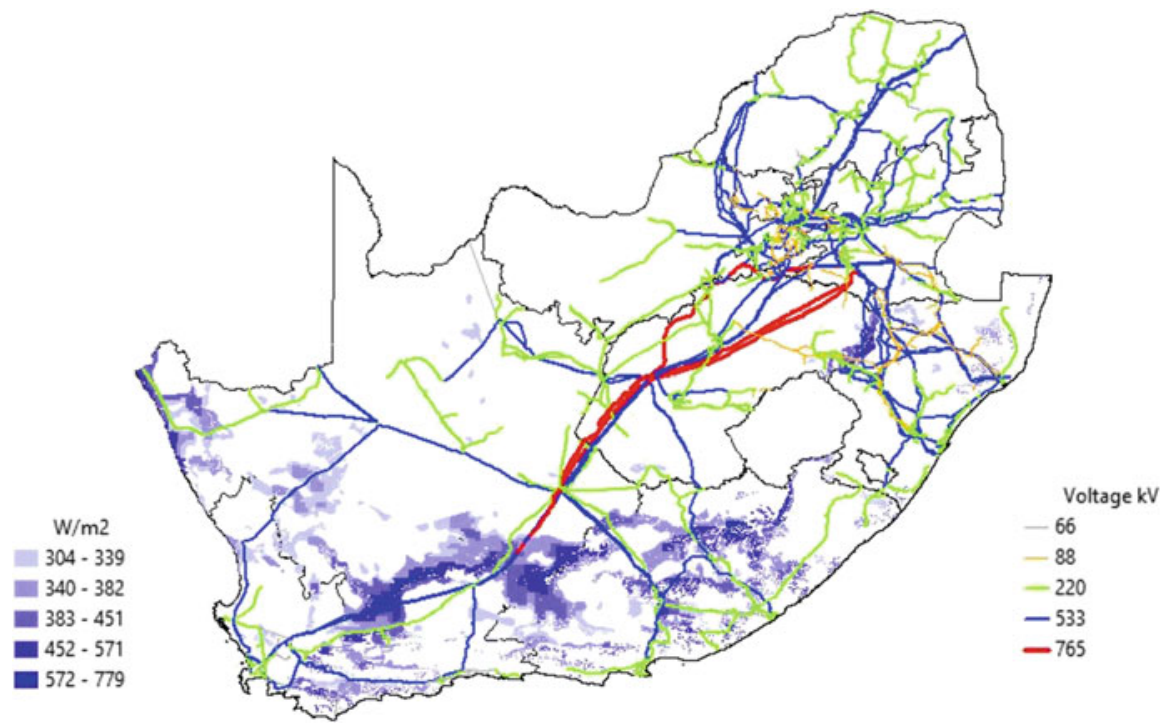

Fig. 3.23 South Africa electricity grid and most relevant wind potential. Source: Authors' elaboration on IRENA—REmap (2017)

medium term. Concerning wind potential, most of South African costal promontories have wind speeds exceeding $6 \mathrm{~m} / \mathrm{s}$ corresponding to $200 \mathrm{~W} / \mathrm{m}^{2}$ of potential. The first large scale wind farm (100 MW) of Eskom started production in 2015, and of the $4.36 \mathrm{GW}$ of wind-targeted by $2030,2.67 \mathrm{GW}$ have already been procured. The Department of Energy established the South African Wind Energy Programme in 2008 to provide dedicated support for wind energy development in the country, both at the industrial and R\&D level, and to periodically update the South African Wind Atlas. Finally, South Africa faces various water scarcity issues, so that hydro-power does not play a particularly relevant role in its energy mix: the country currently imports $1300 \mathrm{MW}$ of hydroelectricity from Mozambique, and further domestic potential is low.

\subsubsection{RE Policy Framework}

In November 2016, South Africa's government presented the Integrated Resource Plan, which outlines the country's electricity strategy to 2050 . Under the plan, the country seeks to add $37 \mathrm{GW}$ of wind plants and $18 \mathrm{GW}$ of PV by 2050 , while reducing the share of coal in its generation portfolio from over $75 \%$ to $20 \%$. Note that RE feed-in tariffs were experimentally introduced in 2009, but were quickly 
phased out and replaced by market-based and competition-favouring programs, namely the REIPPPP competitive bidding framework. As a result, IPPs are beginning to enter the market with renewable projects even though many of them continue to face delays (even those at advances stages) due to financial issues. A regulatory framework to complement the program is expected to be submitted in 2018. In previous years, the introduction of a carbon tax has also been discussed, with the side-objective of rendering renewables deployment more attractive. However, the introduction of the tax has been deferred several times as it would represent a highly impactful policy for the country industrial sector given the large financial implications for ESKOM and the mining sector. It is also worth noting that a biofuels blending mandate was supposed to come into force in 2015, but the government had not released neither the pricing nor the final position paper.

\section{References}

Africa Oil Corp. (2016) Africa oil announces significant increase 2C oil resources. http:// africaoilcorp.mwnewsroom.com/Files/0c/0c181237-25da-4bb4-84af-bf5bedfe20f1.pdf

CIA (2017) The world factbook 2017. https://www.cia.gov/library/publications/the-worldfactbook/

Climatescope - Bloomberg New Energy Finance (2017) Climatescope 2017. http://globalclimatescope.org/

ENI (2017a) Volume 2-World gas and renewables review 2017.. https://www.eni.com:443/en_IT/ company/fuel-cafe/world-gas-e-renewables-review-2017.page. Accessed 15 Jan 2018

ENI (2017b) Volume 1-World oil review 2017.. https://www.eni.com:443/en_IT/company/fuelcafe/world-oil-gas-review-eng.page. Accessed 15 Jan 2018

ESCOM (2017) Electricity Supply Corporation of Malawi Limited (ESCOM). http://www.escom. $\mathrm{mw} /$

Gordon E (2018) The politics of renewable energy in East Africa. Oxford Institute for Energy Studies. https://www.oxfordenergy.org/publications/politics-renewable-energy-east-africa/. Accessed 3 Sep 2018

IEA (2017a) World energy outlook 2017

IEA (2017b) WEO 2017 special report: energy access outlook. International Energy Agency

IRENA - REmap (2017) Remap: roadmap for a renewable energy future. International Renewable Energy Agency, Abu Dhabi

Kenyan Energy Regulatory Commission Energy Regulatory Commission. In: Energy Regulatory Commision. https://www.erc.go.ke/

Korkovelos A, Mentis D, Siyal S et al (2018) A geospatial assessment of small-scale hydropower potential in Sub-Saharan Africa. Energies 11:3100

Renewable Energy Atlas Mozambique (2014) Atlas das energias renováveis de Moçambique. http://atlas.funae.co.mz/

RISE (2017) RISE renewable indicators for sustainable energy 
The International Journal on Hydropower and Dams (2017) Hydropower and dams in Africa 2017. https://www.hydropower-dams.com/product/africa-map-2017/

The World Bank (2017) World bank data. https://data.worldbank.org/

United Nations (2015) Resolution adopted by the general assembly on 25 September 2015: transforming our world: the 2030 agenda for sustainable development

Open Access This chapter is licensed under the terms of the Creative Commons Attribution 4.0 International License (http://creativecommons.org/licenses/by/4.0/), which permits use, sharing, adaptation, distribution and reproduction in any medium or format, as long as you give appropriate credit to the original author(s) and the source, provide a link to the Creative Commons license and indicate if changes were made.

The images or other third party material in this chapter are included in the chapter's Creative Commons license, unless indicated otherwise in a credit line to the material. If material is not included in the chapter's Creative Commons license and your intended use is not permitted by statutory regulation or exceeds the permitted use, you will need to obtain permission directly from the copyright holder. 